\title{
Policy Responses to the COVID-19 Crisis: Dependence on Local Governments for Long- Term Stability
}

\author{
Thokozani I. Nzimakwe \\ ORCiD ID: https://orcid.org/0000-0001-5817-9910
}

\author{
Nokukhanya N. Jili \\ ORCiD ID: https://orcid.org/0000-0001-7785-9583
}

\begin{abstract}
The current crisis (COVID-19) is the recent pandemic to hit all countries in the world. The crisis this time is certainly different, as it is an event suddenly emerging from the health sector, and spreading throughout the entire world, irrespective of geography and social structure. It is threatening all of mankind. Households who lose their income directly or indirectly because of containment measures will need government support. This requires the formulation of policies to address such a crisis and pandemic. In many parts of the world, leaders are forced to take extreme measures like declaration of a national emergency, leading to lockdown of all activities except essential services, apart from social distancing. If policy space is not created at the earliest opportunity, responding to the crisis may be difficult. A crisis like this one is affecting rural and urban areas and can simultaneously take over large metropolitans and small urban centres. It can cause devastation in neighbourhoods as well as in all districts, and can spread over the most diverse geographies. The participation of local governments in combating the crisis seems natural and uncontrolversial as a sphere closer to communities. This paper investigates the role of local governance in crisis-stricken areas, through a qualitative approach by analysing and synthesising literature in terms of a desktop study methodology. Local governments are the best positioned to address crises because of their proximity, legitimacy, and durable presence in their communities.
\end{abstract}

Keywords: Crisis; pandemic; disaster; local government; public policy; communities; stability. 


\section{Introduction}

Local governments face a variety of crises, such as natural disasters and environmental threats, financial meltdowns, epidemics and explosions, and technology failures. Crises are not routine events such as fires or traffic accidents. Crises are incredible events that often take politicians, leaders, and citizens by complete surprise. A crisis, like COVID-19, occurs when a community of people, an organisation, a city/town, or a nation, perceives an urgent threat to core values or life-sustaining functions that must be urgently dealt with under conditions of deep uncertainty.

These dramatic events create tough challenges for public authorities and institutions. Critical decisions must be made and implemented under considerable pressure, with tight deadlines and in the absence of essential information about causes and consequences. Even if the conditions for effective action are severely hampered, citizens expect governmental leaders and public authorities to safeguard them from the threat at hand. The impact of COVID-19 pandemic has influenced the capacity of governments to cope with and counteract its consequences.

This paper investigates the role of local governments in combating crises, and the public policy responses in times of crises and pandemic. The paper points to the rapid rise in poverty challenges, especially in developing countries without comprehensive social protection and policies in the wake of any global crisis. Due to COVID-19, many people may fall into, or be trapped in, extreme poverty because of a global crisis, while the number of people living in hunger in the world might rise.

\section{Research Methodology and Approach}

This article expands on previous research by focusing on all spheres of government, especially local governments and their communities, on what they can do to fight the crises and pandemic. This is done through an investigation of the main characteristics of role of local governments in combating crises, and the public policy responses in times of crises and pandemic. Thus, the article employs the descriptive research approach and data was collected by way of a desktop analysis. The descriptive research approach is a basic research method that examines the situation as it exists in its current state. The descriptive approach involves the identification of attributes of a particular 
phenomenon based on an observational basis, or the exploration of correlation between two or more phenomena (Williams 2007:67). The descriptive research employs the use of correlational, development design, observational studies, and survey research. These research methods may also be used in both experimental and causal comparative research. According to Monette, Sullivan, DeJong and Hilton (2011:35), descriptive research is describing the phenomenon being studied. Descriptive research is used to discover and gain adequate understanding about the present state of a particular situation or event. The paper adopted a qualitative approach by comparing, contrasting, critically analysing and synthesising relevant documentary and literature sources in terms of a desktop study methodology.

\section{Public Policy and Policy Making}

Public policy-making in South Africa is regarded as an ongoing and interactive process. Booysen in Venter and Landsberg (2006:175) states that it can be assessed in terms of a contextualised, cumulative and integrated stream of actions that combine to deliver policies, directives for their implementation, and continuous midstream adaptations of the policy in order to achieve the policy objectives. Colebatch and Hoppe (2018), quoted by McConnell and Hart (2019: 646), suggest that policy can be the structured interactions of governance networks, as well as the process of problematising issues. What is common in the public policy debate is about what constitutes 'policy', and a bias towards the study of policy activity, and a considerable neglect of policy inactivity.

Policy-makers of the most ambitious sort aspire to 'make policy' in that general rule-setting way, envisioning administrators applying those general rules to particular cases in a minimally discretionary fashion (Goodin, Rein \& Moran 2018:15). Policy is formulated in response to problems and challenges. A policy developed to respond to a crisis need to have three objectives; it must guarantee the functioning of essential sectors, provide enough resources for people hit by the crisis, and prevent excessive economic disruption. Innovation policies need to be adapted to conditions both in terms of how such policies are crafted to work for the medium- and long-term initiatives. Local governments need to play their part in managing a crisis. However, it is a relatively new and quite complex action which has led to questions being asked, such as: are local governments endowed with the 
power, resources and capacity to develop and put in place anti-crisis plans and programmes? From a classical economic policy perspective, the existence of a particular public policy requires four basic elements to come together to solve or manage a crisis (Avila \& Monzón 2018:9).

This paper investigates the role of local governments in combating crises, and the public policy responses in times of crises and pandemic. The idea is to develop an understanding of the similar forces driving policy change, where the political interventions plays a crucial role. Building on the work discussed above, Hogan and Feeney (2012:4) hypothesize that policy change occurs in three stages: initiation of the policy debate due to a crisis, idea to change, and the initiation of the policy implementation.

In essence, the intellectual focus of public policy has always been on the design, implementation and evaluation of policies as purposeful government interventions in social processes that need to be carefully calibrated before being put into practice or changed in the light of experience (Peters 2019:45). Accordingly, the study of public policy over the past halfcentury and more has seen thousands of studies describing, explaining and evaluating policy interventions across a multitude of policy areas (McConnell \& Hart 2019:646).

Policy-making followed already institutionalised patterns in the respective countries resulting in different strategies to cope with the crisis in different countries (Kiess, Norman, Temple \& Uba 2015:8). Institutions are the framework of possibilities in which actors pursue their interests and in the case of economic crisis institutions shape solutions to the crisis. More narrowly defined, policy makers act within policy paradigms which structure their crisis responses:

Policy paradigms are the world views of bureaucrats, politicians, and other key political actors about the nature of policy problems and the range of potential and appropriate solutions. These paradigms constitute roadmaps that provide actors with cognitive tools and directions about how to interpret how key macro-institutions (like the economy) function. These cognitive understandings, in turn, shape the range of policy alternatives that come into focus (Immergut \& Anderson 2008:358).

The institutionalist school would expect that even at the times of crisis, the 
policy makers follow their learned paradigms. The argument by Kiess et al. $(2015: 8)$ is that path departure is very unlikely and the initial crisis response is in the line with this argument:

The various responses to the crisis across the range of industrialized countries make the point that there has been no new paradigm for governance emerging as a result of the crisis. Having a new paradigm requires new ideas and those appear to have been in rather short supply.

Crises or sudden shocks are often cited as explanations for policy change, as their existence highlights a failing within existing policies due to their implication in, or inability to correct an emergency situation. In order for policy-makers to challenge existing arrangements, a crisis and policy failure must be identified and widely perceived. Policy exerts must diagnose, and impose on others, their notion of a crisis before collective action to resolve the resultant uncertainty can be taken. Further, Hogan and Feeney (2012:5) state that agents shape 'the terms of political debate: they frame issues, define problems and influence agendas'.

Policies formulated need to focus on crises, pandemics and disasters occurring in local government.

\subsection{Crisis, Pandemic and Disasters}

Countries throughout the world have been severely hit by COVID-19 crisis, putting them at the epicentre of crises, pandemics and disasters. In spite of the general negative impact, when comparing cities, the recorded differences are significant. According to Cohen (2011:26), understanding such differences can provide us with important keys in discerning why some countries are more developed, productive, innovative, and more capable of pulling through crises than others.

Boin, Hart and McConnell (2009) quoted by Steinebach and Knill (2018:1567) identify three constitutive elements of a crisis: the perception of threat, urgency, and uncertainty. Crises presume that a community perceives a threat to its core values or life-sustaining functions, such as welfare, health, safety or security. Urgency means that a lack of time is a defining element of crises. There is a common feeling that the threat is real and must be dealt with 
as soon as possible. Finally, threat and urgency are accompanied by a considerable uncertainty over the nature of the threat and its potential consequences.

While global crises such as pandemics, financial recessions, forced migration, and security threats vary in scope and length according to economic, political, and other cycles, what is common is how states and nations react to such crises. According to the International Labour Organization (2011:4), the global crises have underlined the vulnerabilities of the millions of workers who lost their job and, with it, access to any source of income or health coverage. In the modern era, the inadequacy of policy responses to address any crisis exposes a paradigm resistant to change but also mark a historical contingency of similar gravity. Further, in the modern era, the global community will be confronted with a variety of global crises: climate change, ecological degradation, food and water insecurity, emergent pandemics, and demographic shifts. In recent years, many governments around the world have developed a new generation of social economy policies to address the impacts of crises (Avila \& Monzón 2018:48).

The issue faced by policy practitioners (public servants involved in the policy making process at any stage) is that Enlightenment rationality, the epistemic underlying the modernist problem-solving approach, treats every problem as tame (Hartley, Kuecker \& Woo 2019:2). While that approach worked in an era lacking any concept of a 'global crisis', it is not well-suited for the modern era, yet old ways of understanding and addressing problems are surprisingly slow to pass. Hartley, Kuecker and Woo (2019:2) further argue that policy practitioners must understand that the current way of addressing any crisis is outdated and that a transition to a predicament thinking-based policy paradigm is needed.

Public policies formulated need to address any type of social, economic and global crisis, as highlighted in the next section.

\section{Social, Economic and Global Crises}

The global economic downturn has had wide-ranging negative social outcomes for individuals, families, communities and societies. Poverty and unemployment have been linked to crime, gender-based violence, substance abuse and mental illness, including depression and suicide. During times of financial and economic crisis, households often adopt coping strategies, such 
as making changes in household expenditure patterns; however, these can negatively influence education, health and nutrition outcomes, which may lead to lifelong deficits for the children affected and thus perpetuate intergenerational poverty (Department of Economic and Social Affairs [DESA] 2011:4-5).

\subsection{Need for Social Protection}

The devastating impact of COVID-19 on so many people underscores the dynamic and multidimensional nature of poverty and the critical importance of social protection for reducing vulnerability. Countries that have social protection systems can better mitigate the negative impacts of shocks and prevent people from falling deeper into poverty. Social protection measures can also help regenerate economic activities and livelihoods (DESA 2011:9). Social protection can be enhanced by formulating social and public policies that talk to crises.

Social policy is an inclusive discipline, which means it needs to provide solutions to address needs of social life. Social problems change, based on economic and environmental factors. These changes also differ based on social structure and state policies. In a broad sense, the concept of social policy means comprehensive practices which address not only the problems and needs of working class, but also those of the other segments of society (Steinebach $\&$ Knill 2018:1568). With a definition from this perspective, Aravacik (2018:3) states that it is possible to say social policy discipline addresses the problems of urbanisation, environment, health, and education, and those from all sectors of society such as workers, the disabled, the elders, children, and immigrants. In a broad sense, social policy emerged together with the concept of welfare state after World War II. Therefore, social policy includes health services, social security, city, environment, and struggling against unemployment and poverty that affect social welfare. The final target of all these practices is to ensure social peace, social justice, and equality between different groups (Kiess et al. 2015:10-11).

In the long term, social protection can help individuals and families build human and social resources, among other assets, and improve their livelihood prospects, thereby reducing poverty and unleashing the productive potential of the workforce. Therefore, social protection should not be viewed as a temporary measure to cushion the impact of a crisis, but rather as an 
ongoing investment to promote sustained, inclusive and equitable economic growth. If social expenditures are allowed to decline in the wake of the crisis, such a situation is likely to exacerbate and prolong the adverse impacts of the crisis, for example, on levels of malnutrition, school dropout rates and longterm unemployment (DESA 2011:9).

Universal access to basic social protection and social services is necessary to break the cycle of poverty and reduce inequality of access to resources. A human rights-based development strategy must advance the full realisation of social and economic rights, and should also, for example, advance and protect gains in social development during times of crisis (DESA 2011: 9-10).

\subsection{Economic Crisis}

Economic crises have served as a reminder that it is essential for people to be healthy, educated, adequately housed and well fed to be more productive and better able to contribute to society. In other words, social policy in general, as well as measures to end poverty in all its dimensions, should be an integral part of macroeconomic policy to promote development. Local governments can also play a role within their mandates to solve economic crises. Approaches to poverty reduction should, therefore, be developmental and holistic, integrating economic and social policies to achieve people-centred development outcomes (DESA 2011:10-11; Kiess et al. 2015:15-16).

In the context of the crisis, a job-rich recovery requires incorporation of social objectives into economic recovery strategies and policies. In fact, macroeconomic policy measures to promote sustained recovery should support policies for employment growth and poverty eradication. Social objectives should be accorded priority in recovery strategies and development policies (DESA 2011: 11). An economic crisis presents an opportunity to raise investment in human capital. Such a crisis requires policy reforms which will improve the incentives for innovation, as they remove distortions in the market (OECD 2009:14).

The global economic downturn has had wide-ranging negative social outcomes for individuals, families, communities and societies, and its impact on social progress in areas such as education and health will only become fully evident over time. During times of financial and economic crisis, households often adopt coping strategies, such as making changes in household expendi- 
ture patterns. However, these can negatively influence education, health and nutrition outcomes, which may lead to lifelong deficits for the children affected and thus perpetuate what DESA (2011: iii) calls the intergenerational transmission of poverty. The global crisis of 2009 gave an opportunity to rethink the pattern of global growth that would lead to employment recovery, which is productive (International Labour Organization 2011:3).

Financial crises, such as that of 2008-2009, cause GDP to decline, trade to shrink, unemployment to rise, and social problems to increase. Social security serves many purposes for individuals, businesses, and the state. It helps individuals to smooth consumption over the life cycle and during macroeconomic downturns. It facilitates job mobility and job matching. It supports human capital formation for long-term growth and, by acting as an automatic stabiliser, it facilitates economic stability. If well-designed, social security spending does not only address immediate needs but can also translate into better crisis preparedness and better public policy in the future (Prasad \& Gerecke 2010). Looking historically, crises have played defining roles in developing and strengthening public policy. During times of crisis, it also becomes the responsibility of local governments to assist national governments with managing and solving economic crises.

\subsection{Risks in the Design and Implementation of Social Economy Policies}

If social economy policies are intended to maximise the potential contribution of the social economy in solving substantive issues facing societies, to generate innovation and to offer a response to the huge challenges in countries worldwide, government must avoid conceiving these policies from partial, instrumental and top-down perspectives (Avila \& Monzón 2018:48). The risk stems from undervaluing the potential of civil society itself in leading social and economic development projects, supported and catalysed by public institutions. Organised civil society is ultimately the bearer of social needs, the problems to which a response is to be given and the innovations that reveal its aspirations. Avila and Monzón (2018:49) argue that it is the social engine of the social economy that the social economy policies (SEPs) must support. An excessive one-sided top-down approach, with insufficient involvement of organised civil society in the design and implementation of SEPs, is a major conceptual mistake, which also affects the continuity of these policies. 


\section{Role of National Government in a Crisis}

The role of the national government in emergency management is similar in many ways to that of local government. National government must have an effective organisation and develop and maintain necessary plans, facilities, and equipment. This is because most policies are formulated at a national sphere. On a day-to-day basis, the implementation of policies becomes the responsibility of other spheres. The state is the key for collecting information and assessing the problem, and then deciding the course of action to take. National government provides direct guidance and assistance to its local jurisdictions in programme development and channels guidance and assistance down to the local level. In an emergency or crisis, it ensures a coordinated response through the combined efforts of local government, provincial agencies, and private sector organisations. National government has a strong mandate to prepare for and respond to disasters. In South Africa, this mandate by national government is derived from the Constitution.

It is essential that governments take into account the likely social implications of their public policies. The Report on the World Social Situation by the Department of Economic and Social Affairs (DESA 2011: iv) has shown, time and again, that public policies considered in isolation from their social outcomes can have dire consequences for poverty, employment, nutrition, health and education, which, in turn, adversely affect long-term sustainable development and long-term economic growth. A disconnect between public policies and their social consequences can create a vicious circle of slow growth and poor social progress. Universal social protection systems and active employment generation programmes should become permanent measures, not merely temporary components of national crisis response measures. Governments need to act quickly and massively to address the consequences of any crisis (International Labour Organization 2011:13).

Proper government reaction to socio-economic crisis has long been a central element of public policy debate and is experiencing a revival after the great financial crisis of 2008. Previous studies argue on theoretical and empirical grounds that crises may lead to more interventionist policies, but also cause deregulation and liberalisation (Bjornskov \& Rode 2018:816).

\section{Role of Local Government}

The participation of local governments in combating the crisis seems natural 
and uncontroversial. However, it is sometimes a complex and challenging action which has led to questions being asked, such as: are local governments endowed with the power, resources and capacity to develop and put in place anti-crisis plans and programmes? Can their actions really be effective? Can they make a difference and counteract the effects of any crisis? Is it not misguided to think that local governments can 'solve' the current situation when it is known that powerful forces are to be found in other places and that other more powerful economic and political actors are the ones that have the last say in this process? (Cohen 2011:2).

Chapter 7 of the Constitution of the Republic of South Africa of 1996 sets out a framework for local government. It requires municipalities to be established for the whole territory of South Africa, and provides for three categories of municipalities, whereby some areas are governed by a single 'Category A' municipal authority and others are governed by a two-level system with a larger 'Category C' municipality containing multiple 'Category B' municipalities. The municipalities are granted the power to administer certain matters listed in Schedules 4 and 5, and the executive and legislative authority is vested in the municipal council (RSA 1996).

Cohen (2011:2) concurs with the idea that local governments should and can get involved actively and responsibly in combating the crisis but, at the same time, policy analysts understand that this intervention has its limits, and these should be identified. It is a sphere of action that requires local government to have real and effective powers and capacities. In the end, the instruments that are likely to be applied to avert crisis should be the right ones and should be designed to achieve precise and specific objectives.

Communities have to be careful to avoid thinking that the existence of 'formal' comprehensive plans with a long-term approach will guarantee that policies will be more successful than in municipalities that do not have such plans. Actually, many local governments that have been especially active and have been efficient in fighting the crisis have strategies that are right on the mark for such an undertaking, even if they do not have formal plans drafted to fight the crisis (Cohen 2011:22; Kuban 1996:242).

In South Africa, every municipality must have a disaster management plan as part of its Integrated Development Plans, according to the Municipal Systems Act No 32 of 2000 (RSA 2000). In each municipality, the Community Services department is responsible for disaster management. Local government has the primary responsibility for emergency or crisis 
response, but there are times that a crisis overwhelms the local municipalities' capacity for effective response. The national government office of emergency management operations function includes activities that are essential to a coordinated response in support of a local jurisdiction.

\section{Public Policy Change at the Times of Crisis}

Whether a government is actually (and literally) 'doing nothing', can be a point of argument. In the face of a humanitarian emergency in most countries, media and political opponents may accuse the government of 'doing nothing' to help resolve the crisis, yet government may say it is 'doing everything' it realistically can. Hartley, Kuecker and Woo (2019:15) argue that if the public policy discipline ignores the biggest challenge like a crisis or pandemic, the complexity of global systemic crises like climate change or economic downturn and the failure of existing policy paradigms to provide more than incremental and middling responses, it does so at disservice at risk to policy practice and humanity itself.

How, therefore, can societies identify instances of policy inaction in a politically as well as analytically meaningful manner? It becomes clear that policymakers, governments, organisations and networks are inclined to select which issues are of potential relevance to them, and marginalise or exclude those on which they do not wish to devote their attention or resources. If policy makers inevitably do not do things they theoretically could do in a particular instance or on an ongoing basis, the argument becomes how communities single out cases of inaction (McConnell \& Hart 2019:648).

During a crisis, government may decide to be involved (action) or not involved (inaction). McConnell and Hart (2019: 648) define policy inaction, therefore, as an instance and/or pattern of non-intervention by individual policymakers, public organisations, governments or policy networks in relation to an issue within and potentially within their jurisdiction and where other plausible potential policy interventions did not take place.

A crisis also provides an opportunity to re-examine approaches to public policies. The fact that populations in rich and poor countries alike have been negatively affected by the global food, financial and economic crises underscores the case for a universal approach to public policy that does not focus only on people already in poverty. Universal social provisioning should be the goal of social policy making and will also ensure broader and more 
sustained support than narrowly targeted policy measures which risk significant notwithstanding unintended exclusion of many of the deserving (DESA 2011:11).

The crisis presents an opportunity for developing countries to introduce or improve their weak or non-existent social security and expand on their limited capacity for information-gathering and programme evaluation. Crises also allow countries to reduce or remove ineffective policies in favour of equitable ones that promote long-term growth and better risk management. In the past, many countries have capitalised on this opportunity and successfully exited from their crises, while also improving their policy frameworks in the long term (Prasad \& Gerecke 2010).

\section{Policy Development to Respond to a Crisis}

A policy developed to respond to a crisis need to have three objectives: firstly, it must guarantee the functioning of essential sectors; secondly, provide enough resources for people hit by the crisis, and finally, prevent excessive economic disruption (Hartley et al. 2019:2).

Crises demand fast and effective whole of government responses, and it is important to establish political will and authority early to drive policy development and response. Clear understanding of the role and responsibility of all of those involved in the response is also critical. A focus on rigorous policy development and implementation is important in driving the dynamic from crisis to recovery. At the same time, strategic use of partnerships outside government can also be valuable. It is important that crisis management protocols and practices keep pace with changes in the nature of potential threats, environment, technology and political imperatives. Effective and integrated public policy development and management is critical during crises. Hogan and Feeney (2012:4) state that while politicians are present in the core decision-making network, it is policy entrepreneurs who dominate this process.

McConnell and Hart (2019:653), citing Janis and Mann (1977), identified several patterns of coping with the pressures of responsibility under which policymakers labour that may conduce them towards inaction:

- Unconflicted adherence to the status quo, by selective attention to information about past, present or future conditions and selective interpretation and forgetting of information that conflicts with their 
gentle interpretation of the status quo;

- Shifting responsibility ('buck passing') for taking a decision or acting on a signal to other people, departments or organisations;

- Bolstering decisions already taken in the past by rationalising away the need to reconsider them;

- Procrastination i.e. continued indecision while searching for more information, engaging in further deliberation or determining to defer the making of a decision.

These coping mechanisms make for observable patterns of behaviour that indicate individual policy makers' propensities for non-acting or for choosing not to change pre-existing policies. A key conclusion on policy development is that countries need to be able to pursue counter-cyclical policies in a consistent manner. Such policy space should be enabled by changing the fundamental orientation and nature of policy prescriptions that international organisations impose on countries as conditions for assistance (DESA 2011:3). Policy development has to be guided by leadership provided and how a crisis is managed.

\subsection{Leadership and Public Policy Environment Crises Management}

As leadership is always necessary for successful public policies, in times of crisis, leadership becomes a matter of crucial importance. In a crisis, successful public policy is directly linked to the importance that presidential authority gives the conflict, its own interest in finding a solution and to the content that the authority wants to give such initiatives (Baraona 2011:133). Crisis management (prevention, preparedness, response, and reconstruction) is a tough task for political and bureaucratic leaders. The very occurrence of a crisis is then thought to expose the status quo as problematic, making it easier to gain momentum for alternative policies and institutions. Boin and Hart (2003:544) argue that the opportunities for reform in the wake of crisis are smaller than often thought. The prime reason is that the requisites of crisis leadership are at odds with the requirements of effective reform. When crisis leadership results in reduced stress and a return to normality, people herald their 'true leaders'.

According to Hartley et al. (2019:7), ensuring systemic leadership capabilities is dependent on the promotion of inter-governmental, inter- 
organisational, and inter-sectoral collaboration. The benefit of this approach is on collective capacity and gains from cooperative synergies. Such collaboration also builds redundancy and resilience into crisis preparedness systems, and can encourage progress toward harmonisation of managerial practices across the broader policy ecosphere. Finally, systemic political variables are crucial for building and protecting policy capacity to address global crises and their local manifestations. Based on the assumption that robust preparedness involves open communication, along with a critical and introspective approach to analysing policy options and implementing solutions, governments should ensure a political environment that promotes free exchange of ideas and democratic responsiveness in policymaking (Hartley et al. 2019:7).

Boin and Hart (2003:551) speak of leaders as people in senior positions in governments and public organisations, whether they are political appointees or career bureaucrats. They contend that there are three lessons that may assist crisis leaders to avoid reform-induced crisis:

- Leaders need to formulate a crisis management philosophy, which can help to negotiate the inherent dilemma of reparation and reform;

- Leaders should not push reform without considering opposite arguments. If they use the crisis to ignore critics, they will mobilise their own opposition at a time when their performance is already under scrutiny, and

- Crisis-induced reform creates exceptional challenges for the long term.

\section{The Participation of Local Governments in Combating A Crisis}

This section highlights the way local governments have integrated a wide variety of policies such as those that relate to public, social and economic policies. Local governments in South Africa implements various policies initiated by the national government and have to direct their resources to them for implementation. Public policies applied in response to the crisis in urban settings undoubtedly are quite significant in determining the situation os a given city. However, their effect is difficult to evaluate for three reasons: first, very little time has passed since the onset of the crisis; second, there is a broad array of measures that different levels of government have applied, 
complicating the possibility of a specific rigorous analysis; and third, thousands of local governments exist around the world and we have information from only a few (Cohen 2011:18).

Some local governments have assigned their resources to help rescue businesses, especially metropolitans with large budgets in South Africa. Others have emphasised measures of a social nature, such as benefits for the unemployed and for the poorest part of the population, while other local governments have developed more comprehensive plans that combine actions in several areas. Moreover, several local governments have integrated their crisis-fighting programmes and actions into their strategic plans that they may have had prior to disasters.

Several cities have developed plans or programs intended specifically to face the crisis. According to Cohen (2011:22), evaluations have to be conducted in an attempt to determine if formal anti-crisis plans exist, that is, approaches integrated into a document containing all elements of a programme with a comprehensive vision covering different aspects for the short, medium and long-term views. Crisis periods (or disasters) are abnormal and unique events that occur with some degree of surprise and demand unusual, extensive and taxing response efforts. Kuban (1996:239) states that crises require local governments to make rapid, timely, effective and appropriate decisions on a scale rarely experienced during day-to-day operations. Poor, untimely or inappropriate decisions could result in increased fatalities, injuries and property losses.

Local governments may not be able to change the course of large events. They do not control the large macroeconomic variables (monetary, credit, tax, expenditure, international trade policies), and frequently do not even have enough tax resources or the legal power to decide how to spend them. In terms of the Constitution of 1996, these are performed at a national level (RSA 1996). On the other hand, they do have many advantages, such as a collection of local revenue and powers to make bylaws. These can be used to address challenges of pandemics through political and institutional agreements, and social relations. The main advantage is that they are in touch with the people. This is what allows them to do many things, for instance, to lessen the effects of the crisis and to lay the basis of their future development (Cohen 2011:26).

A lesson provided to communities by cities that have put in motion highly advanced programmes is that the solution to current problems must be 
for sustainability. This can be achieved by creating new jobs, building modern, sustainable, and technologically advanced infrastructure, and by promoting innovation, human capital formation, and improving urban management. Local governments have these factors within their grasp, especially those that have human and material resources and who have accrued administrative experience in local economic development management and strong political leadership.

The causes of the crisis of the welfare state in developed countries are globalisation, which is an external factor, and internal variables which are related to the social structures of states. Aravacik (2018:11) states that with the shrinkage in the welfare state, the provision of welfare services has also changed. The service provision which had been performed by the state has been given through local administrations at local level, and it has been left to the non-profit organisation, which means it has been 'privatized'.

\subsection{Urban Innovation}

Local governments have taken measures in the arena of urban innovation to fight the crisis. Some municipalities, hard hit by the crises, have adopted shortterm measures such as placing the out of work in new jobs, creating new jobs, and providing financial aid to the unemployed and to poor families. At the same time, local governments have created a series of strategic initiatives designed to achieve recovery in the long term, with a focus on innovation, including new infrastructure to replace old and inefficient infrastructure in order to be ready for the future urban economy. Others have launched initiatives to create Innovation Funds, a programme that targets new ways to fight poverty (Cohen 2011:23).

Within the global context, French and European local authorities have often served to give a voice to their afflicted counterparts. Cités Unies France (CUF) work on the issue of 'crises and rehabilitation' stems from the request by French local authorities eager to help their colleagues in situations of emergency or post-emergency. Their question was the following: how can governments assist local authorities coming out of a critical crisis situation to continue to perform their duties and provide indispensable local public services? (Cités Unies France 2016). Past experience and acknowledgment of the limits to existing systems have led researchers to define a new approach to such post-crisis periods, which follow upon situations of emergency and which unfortunately can last for years. What has been proposed France is what could 
be called a 'local generalist approach'. This is financial and technical assistance to local authorities to enable them to manage all the problems that fragile populations have to face.

The approach in France has been progressively structured around several realisations:

- increasing decentralisation the world over leading both to strong territorial identification and new local political elites with immense responsibility towards their constituents but not always the means to fulfil their duties;

- $\quad$ an increase in the number of weak or failed states unable to fulfil their state duties and to manage crisis situations;

- ever more recognition of the role of local authorities in the development of their country;

- the close links between emergencies, reconstruction and development;

- the rise of multilateral humanitarian assistance with large budgets but little knowledge of local particularities (Cités Unies France 2016).

Given this state of affairs, we have concluded that local authorities and local solidarity networks, are the best positioned to address these difficulties for three reasons: their proximity, legitimacy, and durable presence in their communities (Cités Unies France 2016). The next section deals with policy recommendations for responding to a crisis.

\section{Policy Recommendations for Responding to Crises and Pandemic}

Given the examinations of policy capacity in other countries, and in South Africa, which have gone through crises and pandemics, the question becomes which public policy behaviour (process) or condition (capacity) generates progress, adaptation, and flexibility in responding to crises and pandemic problems. Hartley et al. (2019:7-10) advocate for the following as recommendations in responding to crises and pandemics.

\section{Analytical Capacities}

As part of analytical capacities, effective communication is a key pillar of crisis 
governance. As policies are put together on-the-go to deal with uncertainty and ambiguity, governments have to scramble to contain the crisis while communicating with the public in real-time. Communicating under conditions of uncertainty is characterised by constant tensions and dilemmas. Being transparent and accurate in relaying information; preparing the public for what is coming next; and expressing a degree of empathy in communicating policies can go a long way in ensuring effective crisis communications (El-Taliawi \& Van der Wal 2020).

\section{Political Capacities}

In times of crisis such as the current COVID-19 pandemic and its economic and social repercussions, public governance matters more than ever. Governance arrangements have played a critical role in countries' immediate responses, and will continue to be crucial both to the recovery and to building a 'new normal' once the crisis has passed (OECD 2020). Political capacities provide the foundation on which mutual state-society trust and social capital are built. Connections to grassroots and social service organisations are important for crisis management, since these organisations frequently play a key role in collective action, and frontline responses.

More important than the development of a rigorous and operational assessment methodology for these policies, is the establishment of synthetic indicators, as well as general and specific criteria. Similar to the current challenge of measuring the social and economic impact of the social economy and social enterprises, is the challenge of assessing social economy policies (Avila \& Monzón 2018:48).

At the organisational level, public agencies need to ensure independence and transparency to avoid capture by power brokers, political factions, and elite interests. As with managerial capacities, this can be enforced through the establishment of independent watchdog units and other monitoring and accountability mechanisms. These arrangements provide policy practitioners with real-time access to feedback on a variety of issues from waste management to emergency response. At the systemic level, public consultation and engagement efforts can contribute to greater social trust and a collective approach to problem definition that incorporates residents' views and opinions (Hartley et al. 2019:10). 


\section{Recommendations}

It must be pointed out that many local governments have not developed a crisisspecific policy. In responding to a crisis, national government, which contributes a great portion to municipal income, needs to increase the amount of fiscal resources put aside for local governments. Yet, this approach is not a long-term solution. If national governments decide to cut their budgets heavily, an action that has already seen in some countries, then the local governments will experience a significant decline in resources (Cohen 2011:20).

The reforms in the examined social, economic and broad public policies demonstrate that governments need to use, or should be able to use, the crisis as a window of opportunity for more radical public policy change. In most countries, Kiess et al. (2015:23) recommend that the crisis should push politicians towards well institutionalised policy measures and familiar narratives of the role of the state. On the other hand, even if local governments were to continue receiving resources from the national government, they will not necessarily be able to spend them freely. This is because transfers are sometimes 'earmarked' in many centralised tax regimes, meaning that funding has to be spent on line items predetermined by the national government (Cohen 2011:21).

Hartley et al. (2019:11-12) propose the following recommendations for how policy practitioners can operate in a liminal and transitioning policy environment to respond to crises and pandemic:

- Create organisational structures that favour horizontal leadership and equalise power relations;

- Enable open-source approaches that serve the public commons;

- Incentivise innovation, creativity, sideways thinking, and risk-taking;

- Embrace all forms of diversity;

Based on the desktop analysis, it is recommended that national government and municipalities should take steps to mitigate the damage caused by the COVID-19 crisis. These include restructuring their balance sheets, entering into regional recovery efforts, carefully examining operating costs, adopting job-shares, monetising fixed assets, pruning overheads and working closely with community organisations. Governments need to act and they need to act fast to assure that the government is adequately financed to withstand the 
collapse in tax revenues and the need for increased health and social expenditures.

What local governments, and their communities do to fight a crisis is what is truly important. There are successful and encouraging examples in different regions around the world and in South Africa where local governments have put their best strengths and most compelling creative solutions forward to help themselves survive. Nevertheless, there are cases found in some local governments that just crossed their arms and waited for the crisis to blow over and the problems to magically disappear.

\section{Conclusion}

The immediate and long-term social impacts of any crisis and strongly underscores the need for inclusive social policies. As challenging as it may be, a crisis offers an opportunity for achieving social progress by making public policies for social protection a reality. This can be done by revisiting the social aspects of globalisation and ensuring more inclusive and sustained growth, very much in line with sustainable development's commitment to achieving economic development, social progress and environmental sustainability. A crisis or pandemic offers an opportunity to rethink the role of public policy and social investment in transforming policy responses to the crisis into opportunities to strengthen social development and to achieve more sustained, inclusive and equitable development. It presents an opportunity to reshape the global economic, social and development agenda. There is renewed realisation that social policy considerations, especially productive employment, should be given greater importance within macroeconomic policy.

Public policy in the twenty-first century needs to take some intellectual risks by extending internal conversations about crises problems to debates about systemic instability.

This article has helped to understand that in order to effectively respond to a crisis, policy making is as important as its implementation.

\section{References}

Aravacik, E.D. 2018. Social Policy and the Welfare State. In Public Economics and Finance. Open Access Books. Turkey: IntechOpen: Available at: 
http://dx.doi.org/10.5772/intechopen.82372. (Accessed on 29 May 2020). Avila, R.C. \& J.L. Monzón 2018. Best Practices in Public Policies

Regarding the European Social Economy Post the Economic Crisis.

Brussels: European Economic and Social Committee. Available at:

http://doi.org/10.2864/623436

(Accessed on 14 May 2020).

Baraona, R.E. 2011. Public Policy Making in Times of Crisis. Revista del CLAD Reforma y Democracia. 49,49:123 - 156.

Bjornskov, C. \& M, Rode 2018. Crisis, Ideology, and Interventionist Policy

Ratchets. Political Studies 67,4 : 815 - 833. Available at:

https://doi.org/10.1177\%2F0032321718807858 (Accessed on 15 May 2020.)

Boin, A. \& P. Hart. 2003. Public Leadership in Times of Crisis: Mission

Impossible? Public Administration Review September/October 2003. 63,5:544 - 553.

https://doi.org/10.1111/1540-6210.00318

Booysen, S. 2006. Public policy-making. In Venter, A. \& C. Landsberg (eds.):

Government and Politics in the new South Africa. $3^{\text {rd }}$ Edition. Pretoria:

Van Schaik.

Cités Unies France (CUF). 2016. Local Authorities in Crisis Management: The

Local Generalist Approach. Available at:

file:///\%20Authorities\%20in\%20Crisis\%20Management\%C2\%A0_\%20t he\%20Local\%20Generalist\%20Approach.html

(Accessed on 16 May 2020.)

Cohen, M.P. 2011. Cities in Times of Crisis: The Response of Local Governments in Light of the Global Economic Crisis: The Role of the Formation of Human Capital, Urban Innovation and Strategic Planning. Working Paper. Institute of Urban and Regional Development, University of California-Berkeley.

Department of Economic and Social Affairs (DESA) 2011. The Global Social Crisis. Report on the World Social Situation 2011. United Nations: New York.

El-Taliawi, O.G. \& Z. Van der Wal 2020. Three Lessons in Crisis Governance for the Age of Coronavirus. The World Economic Forum. April 2020.

Goodin, R.E., M. Rein \& M. Moran 2018. Overview of Public Policy: The Public and Its Policies. In Goodin, R.E. (ed.): The Oxford Handbook of Political Science. Oxford: Oxford University Press. Available at: 
https://doi.org/10.1093/oxfordhb/9780199604456.013.0043

(Accessed on 14 May 2020.)

Hartley, K., G. Kuecker \& J.J. Woo 2019. Practicing Public Policy in an Age of Disruption. Policy Design and Practice 2. Available at: https://doi.org/10.1080/25741292.2019.1622276

(Accessed on 14 May 2020).

Hogan, J. \& S. Feeney. 2012. Crisis and Policy Change: The Role of the

Political Entrepreneur. Risk, Hazards \& Crisis in Public Policy 3,2:

Article 6. https://doi.org/10.1515/1944-4079.1108

International Labour Organization 2011. The Global Crisis: Causes, Responses and Challenges. Geneva: International Labour Office.

Kiess, J., L. Norman, L. Temple \& K. Uba 2015. Living with Hard Times: How

Citizens React to Economic Crises and their Social and Political

Consequences. European Union's Seventh Framework Programme.

Kuban, R. 1996. The Role of Government in Emergency Preparedness.

Canadian Public Administration 39,2: 117 - 266.

https://doi.org/10.1111/j.1754-7121.1996.tb00130.x

McConnell, A. \& P. Hart. 2019. Inaction and Public Policy: Understanding why Policymakers 'do nothing'. Policy Sciences 52: 645 - 661. Available at: https://doi.org/10.1007/s11077-019-09362-2 (Accessed on 29 May 2020.)

Monette, D.R., Sullivan, T.J., DeJong, C.R. \& T, Hilton. 2011. Applied Social Research: A Tool for the Human Services. Belmont, CA: Brooks.

Organisation for Economic Co-operation and Development (OECD) 2009. Responding to Rising Seas: Investing in Innovation for Long-Term Growth. Paris: OECD Publishing.

OECD. 2020. Responding to COVID-19: The Rules of Good Governance Apply Now more than Ever! Available at:

http://www.oecd.org/governance/public-governance-responses-tocovid19/ (Accessed on 05 September 2020.)

Peters, B.G. 2019. Policy Problems and Policy Design. Cheltenham: Edward Elgar. https://doi.org/10.4337/9781786431356

Prasad, N. \& M. Gerecke. 2010. Social Policy in Times of Crisis. CEPR Policy Research 10 October 2010.

https://doi.org/10.1177/1468018110366627

Republic of South Africa. 1996. Constitution of the Republic of South Africa of 1996. Pretoria: Government Printers. 
Republic of South Africa 2000. Municipal Systems Act No 32 of 2000. Pretoria: Government Printers.

Steinebach, Y. \& C, Knill. 2018. Social Policies during Economic Crises: An Analysis of Cross-national Variation in Coping Strategies from 1980 to 2013. Journal of European Public Policy 25,11: 1566 - 1588.

https://doi.org/10.1080/13501763.2017.1336565

Williams, C. 2007. Research Methods. Journal of Business \& Economic Research 5: 65 - 72.

Ian A. Nzimakwe Associate Professor School of Management, IT \& Governance University of KwaZulu Natal Nzimakweth@ukzn.ac.za

Nokukhanya N. Jili Senior Lecturer and Acting Head of Department Department of Public Administration University of Zululand JiliN@unizulu.ac.za 